\title{
Testosterone Therapy and Its Monitoring in Adolescent Boys with Hypogonadism: Results of an International Survey from the I-DSD Registry
}

\author{
Marianna R. Stancampiano ${ }^{a, b} \quad$ Angela K. Lucas-Herald $^{b} \quad$ Jillian Bryce $^{b}$ Gianni Russo $^{a}$ \\ Graziano Barera $^{a}$ Antonio Balsamo ${ }^{c}$ Federico Baronio ${ }^{c}$ Silvano Bertelloni ${ }^{d}$ Margherita Valiani ${ }^{d}$ \\ Martine Cools ${ }^{\mathrm{e}}$ Lloyd J.W. Tack ${ }^{\mathrm{e}}$ Feyza Darendeliler ${ }^{f}$ Sukran Poyrazoglu $^{f}$ Evgenia Globa $^{\mathrm{g}}$ \\ Romina Grinspon ${ }^{\text {h }}$ Sabine E. Hannema ${ }^{\text {i,j }}$ leuan A. Hughes ${ }^{k}$ Rieko Tadokoro-Cuccarok \\ Ajay Thankamony $^{k}$ Violeta lotoval Vilhelm Mladenov' ${ }^{\prime}$ Daniel Konrad ${ }^{m}$ Inas Mazen ${ }^{n}$ \\ Marek Niedziela $^{\circ}$ Zofia Kolesinska $^{\circ}$ Anna Nordenström ${ }^{p} \quad$ S. Faisal Ahmed ${ }^{b}$ \\ ${ }^{a}$ Department of Paediatrics, Endocrine Unit, Scientific Institute San Raffaele, Milan, Italy; ${ }^{b}$ Developmental Endocrinology \\ Research Group, University of Glasgow, Glasgow, UK; 'Department of Medical and Surgical Sciences, Paediatric Unit,

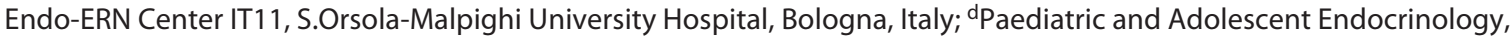 \\ Department of Obstetrics, Gynecology and Paediatrics, Azienda Ospedaliero, Universitaria Pisana, Pisa, Italy; \\ eDepartment of Internal Medicine and Paediatrics, Ghent University and Department of Paediatric Endocrinology,

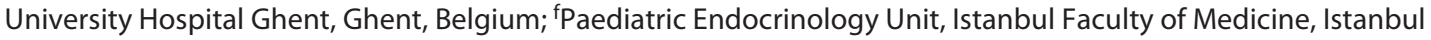 \\ University, Istanbul, Turkey; ${ }^{9}$ Department of Pediatric Endocrinology, Ukrainian Scientific Center of Endocrine \\ Surgery, Endocrine Organs and Tissue Transplantation, MoH of Ukraine, Kyiv, Ukraine; ${ }^{\text {h} C e n t r o ~ d e ~ I n v e s t i g a c i o n e s ~}$ \\ Endocrinológicas 'Dr. César Bergadá' (CEDIE), CONICET - FEl, División de Endocrinología, Hospital de Niños Ricardo \\ Gutiérrez, Buenos Aires, Argentina; 'Department of Paediatric Endocrinology, Sophia Children's Hospital, Erasmus \\ Medical Center, Rotterdam, The Netherlands; 'Department of Paediatrics, Leiden University Medical Centre, \\ Amsterdam, The Netherlands; kDepartment of Paediatrics, University of Cambridge, Cambridge, UK; 'Department of \\ Paediatrics - UMHAT 'Sv.Marina', Medical University of Varna, Varna, Bulgaria; mDivision of Paediatric Endocrinology \\ and Diabetology, University Children's Hospital, Zurich, Switzerland; 'nepartment of Clinical Genetics, National \\ Research Center, Cairo, Egypt; ${ }^{\circ}$ Department of Paediatric Endocrinology and Rheumatology, Poznan University of \\ Medical Sciences, Poznan, Poland; PDepartment of Women's and Children's Health, Karolinska Institutet, Paediatric \\ Endocrinology Unit, Karolinska University Hospital, Stockholm, Sweden
}

\section{Keywords}

Adolescent boys · DSD · Hypogonadism · Testosterone

\begin{abstract}
It is unclear whether testosterone replacement therapy (TRT) in adolescent boys, affected by a range of endocrine diseases that may be associated with hypogonadism, is particularly common. The aim of this study was to assess the contemporary practice of TRT in boys included in the I-DSD Registry. All participating centres in the I-DSD Registry that had boys between
\end{abstract}

karger@karger.com www.karger.com/sxd

Karger $\stackrel{\text { ' }}{5}$

GOPEN ACCESS
(C) 2021 The Author(s)

Published by S. Karger AG, Basel

This is an Open Access article licensed under the Creative Commons Attribution-NonCommercial-4.0 International License (CC BY-NC) (http://www.karger.com/Services/OpenAccessLicense), applicable to the online version of the article only. Usage and distribution for commercial purposes requires written permission.
10 and 18 years of age and with a condition that could be associated with hypogonadism were invited to provide further information in 2019. Information on 162 boys was collected from 15 centres that had a median (range) number of 6 boys per centre (1.35). Of these, 30 (19\%) from 9 centres were receiving TRT and the median (range) age at the start was 12.6 years (10.8-16.2), with 6 boys (20\%) starting at $<12$ years. Median (range) age of boys not on TRT was 11.7 years (10.7-17.7), and 69 out of 132 (52\%) were $<12$ years. TRT had been initiated in 20 of $71(28 \%)$ boys with a disorder of gonadal development, 3 of $14(21 \%)$ with a disorder of androgen synthesis, and all 7
Correspondence to:

S. Faisal Ahmed, faisal.ahmed@glasgow.ac.uk 
(100\%) boys with hypogonadotropic hypogonadism. The remainder who did not have TRT included 15 boys with partial androgen insensitivity, 52 with non-specific XY DSD, and 3 with persistent Müllerian duct syndrome. Before starting TRT, liver function and blood count were checked in 19 (68\%) and 18 boys (64\%), respectively, a bone age assessment was performed in 23 (82\%) and bone mineral density assessment in 12 boys (43\%). This snapshot of contemporary practice reveals that TRT in boys included in the I-DSD Registry is not very common, whilst the variation in starting and monitoring therapy is quite marked. Standardisation of practice may lead to more effective assessment of treatment outcomes.

(C) 2021 The Author(s)

Published by S. Karger AG, Basel

\section{Introduction}

Hypogonadism in adolescent boys may be due to several diseases [Dwyer et al., 2015], and hormone replacement therapy with testosterone $(\mathrm{T})$ is considered one of the cornerstones of the clinical management. In a routine tertiary hospital setting in the United Kingdom, approximately $10-15 \%$ of boys reviewed for suspected hypogonadism may proceed to testosterone therapy [Lucas-Herald et al., 2018]. In childhood, the majority of children with suspected DSD are raised as boys [Rodie et al., 2011], and within a routine clinical setting it is estimated that a quarter of the boys with DSD may have biochemical evidence of hypogonadism [Nixon et al., 2017]. Given that a child with XY DSD and profound hypogonadism is more likely to be raised as a boy nowadays [Kolesinska et al., 2014], it is increasingly likely that there will be more hypogonadal boys who will require androgen replacement in the future. However, currently, unlike girls, there is a relative lack of guidance on sex steroid replacement in affected boys who are reaching the age of puberty [Bertelloni et al., 2008; Stancampiano et al., 2019].

In the absence of clear guidelines for testosterone therapy in boys, the relative rarity of this indication, especially in boys with a DSD and some evidence of variations in practice [Lucas-Herald et al., 2018], there is a need to understand the current practice in more detail. Registered users of the I-DSD Registry have previously participated in surveys of practice [Kyriakou et al., 2016]. Therefore, to understand the variations in practice at an international level, I-DSD centres that had registered boys of a pubertal age with a range of endocrine diseases that may be associated with hypogonadism were approached and invited to participate in a survey of contemporary practice with regard to testosterone replacement therapy.

Testosterone Therapy in Boys with Hypogonadism

\section{Patients and Methods}

Between February and May 2019, those centres that had registered patients in the I-DSD Registry who were male, between the ages of 10 and $<19$ years, and who had a condition that could be associated with hypogonadism were approached to participate in an electronic survey. At the time of the study, there were a total of 1,144 cases categorised as male in the I-DSD Registry, and of these, 225 boys (20\%) from 29 centres were within the suitable age band for inclusion. Of the 29 centres that were approached, 14 (48\%) centres with a total of 174 boys (77\%) agreed to participate, and of these, follow-up data were available in 127 (73\%). In addition to these 127 boys, routinely collected clinical data on a further 35 boys were available from an additional centre, providing a total of 162 cases from 15 centres. The median (range) number of boys per centre was $6(1-35)$.

The questionnaire that was used to collect study data was divided in 2 sections. The first section obtained information on year of birth (YOB), disorder type, diagnosis, karyotype, gonadectomy, and testosterone replacement therapy (TRT) status. Testosterone therapy received in infancy or topical dihydrotestosterone therapy on genitalia were not regarded as TRT. As the I-DSD Registry did not collect the date of birth to estimate the age of each boy at the time of recruitment, all cases were assigned an arbitrary birthday of July, 1st. The second section of the questionnaire was reserved for the subset of patients who were on TRT, and this questionnaire collected information on age at starting hormone therapy, type of therapy, route of administration, dosage, length of treatment, and occurrence of adverse events during testosterone treatment. In addition, the centres were asked to report on any investigations performed at initiation and during therapy. This included auxology, Tanner stage, FSH, LH, testosterone, SHBG, AMH, inhibin B, full blood count, liver function tests, bone mineral density, bone age, sperm count, metabolic, glucose, and bone profile.

The I-DSD Registry is an international database of pseudo-anonymized information deposited by clinicians following informed consent from the patient or their guardian. Details of the development of the Registry and its recent use have been previously reported [Ahmed et al., 2010; Ali et al., 2019], and its standard operating protocol is available at idsdorg.files.wordpress.com/2019/09/ the-i-dsd-i-cah-registry-data-access-policy-v1-290719-1.docx (last accessed, April 9, 2020). The Registry is approved by the National Research Ethics Service in the UK as a research database of information that is collected as part of routine clinical care. Statistical analysis was performed using GraphPad software package (Prism 8 for macOS version 8.0.2, GraphPad Software Inc, San Diego, CA, USA). All data were described as median and range, and comparison of continuous variables was performed using the Mann-Whitney test. A $p$ value of less than 0.05 was considered significant.

\section{Results}

\section{Description of Cases}

The study cohort of 162 boys included 71 (44\%) cases of a disorder of gonadal development (DGD), 15 (9\%) cases of a disorder of androgen action (DAA), 14 (9\%) 
Table 1. Diagnoses in 162 boys with DSD aged 10-18 years in the I-DSD Registry and details of those on testosterone replacement therapy (TRT)

\begin{tabular}{|c|c|c|c|c|c|}
\hline Disorder type & Diagnosis & Total $\mathrm{n}$ & $\begin{array}{l}\text { Boys on } \\
\text { TRT (\%) }\end{array}$ & $\begin{array}{l}\text { Age at start of TRT, } \\
\text { years, median } \\
\text { (range) }\end{array}$ & $\begin{array}{l}\text { Age of boys not on } \\
\text { TRT, years, median } \\
\text { (range) }\end{array}$ \\
\hline \multirow{4}{*}{ Disorder of gonadal development } & Klinefelter syndrome & 19 & $3(16)$ & $15.7(13.3-16.2)$ & $12.7(10.7-17.7)$ \\
\hline & Gonadal regression & 12 & $10(83)$ & $12.0(10.8-14.7)$ & $15.2(12.7-17.7)$ \\
\hline & Ovotesticular DSD & 7 & $4(57)$ & $14.5(13.8-15.1)$ & $11.7(10.7-13.7)$ \\
\hline & Total & 71 & $20(28)$ & & \\
\hline \multirow[t]{5}{*}{ Disorders of androgen synthesis } & $5 a$-reductase type 2 deficiency & 7 & - & - & $11.7(10.7-15.7)$ \\
\hline & $3 \beta$-hydroxysteroid dehydrogenase deficiency & 2 & $1(50)$ & 11.5 (NA) & 17.7 (NA) \\
\hline & 17,20 -lyase deficiencya & 3 & $2(67)$ & $12.5(12-13)$ & $11.7^{*}(\mathrm{NA})$ \\
\hline & P450 oxidoreductase deficiency & 1 & - & - & 10.7 (NA) \\
\hline & $17 \beta$-hydroxysteroid dehydrogenase type 3 deficiency & 1 & - & - & $12.7(\mathrm{NA})$ \\
\hline \multirow{3}{*}{ Hypogonadotropic hypogonadism } & DAX1 variant & 2 & $2(100)$ & $12.9(11.8-13.9)$ & - \\
\hline & Allgrove syndrome & 1 & $1(100)$ & 13.3 (NA) & \\
\hline & Total & 7 & $7(100)$ & & \\
\hline \multirow[t]{6}{*}{ Non-specific DSDb } & Non-specific DSD with EMS $<9$ & 29 & - & - & $11.7(10.7-17.7)$ \\
\hline & Isolated hypospadias & 12 & - & - & $13.2(10.7-17.7)$ \\
\hline & Complex genital anomalies & 6 & - & - & $14.2(10.7-16.7)$ \\
\hline & Non-specific DSD with EMS $\geq 9$ & 4 & - & - & $12.7(10.7-16.7)$ \\
\hline & Isolated undescended testes & 1 & - & - & $11.7(\mathrm{NA})$ \\
\hline & Total & 52 & 0 & & \\
\hline Other & Persistent Müllerian duct syndrome & 3 & 0 & - & $14.7(14.7-16.7)$ \\
\hline
\end{tabular}

${ }^{a}$ Includes one boy with combined 17 -hydroxylase/17, 20-lyase deficiency. ${ }^{\mathrm{b}}$ Non-specific DSD are cases that were not identified as having hypogonadotropic hypogonadism, a disorder of gonadal development, a disorder of androgen synthesis, or a disorder of androgen action. NA, not applicable.

cases of a disorder of androgen synthesis (DAS), 7 (4\%) cases of hypogonadotropic hypogonadism, 3 (2\%) cases of persistent Müllerian duct syndrome (PMDS), and 52 (32\%) cases of non-specific XY DSD (Table 1). The median age (range) of the entire population was 12.7 years (10.7-17.7). Among the 71 boys with a DGD, 29 (41\%) had partial gonadal dysgenesis (PGD), 19 (27\%) had Klinefelter syndrome, 12 (17\%) had gonadal regression, 7 (10\%) had ovotesticular DSD, and the remaining 4 (5\%) included 3 boys with XX testicular DSD and 1 boy with mixed gonadal dysgenesis. All cases of DGD were confirmed by one or more diagnostic methods, including biochemistry, genetics, and gonadal histology. All 15 boys with a DAA were diagnosed as partial androgen insensitivity syndrome (PAIS) with a confirmed pathogenetic variant in the androgen receptor gene. Among the 14 boys with a DAS, 7 (50\%) had $5 \alpha$-reductase deficiency, 3 (21\%) had isolated 17,20 -lyase deficiency or combined with 17a-hydroxylase deficiency, 2 (14\%) had $3 \beta$-hydroxysteroid dehydrogenase deficiency, and there was 1 boy each with P450 oxidoreductase deficiency and $17 \beta$-hydroxysteroid dehydrogenase type 3 deficiency. All these cases were confirmed by biochemistry and/or genetic investigations. The initial presenting features among the 52 boys with non-specific XY DSD included a combination of genital anomalies with a total external masculinisation score (EMS) [Ahmed et al., 2000] of $<9$ out of 12 in 29 (56\%) boys, isolated proximal hypospadias in 12 (31\%) boys, complex genital anomalies in $6(15 \%)$, and isolated bilateral undescended testes in 1 boy.

\section{Testosterone Replacement Therapy}

Of the 162 boys, 30 (19\%) were receiving TRT at the time of the study (Table 1), and these boys were from 9 centres from 9 countries. Of these 30 boys, 24 (80\%) from 9 centres had data available at follow-up. The me- 


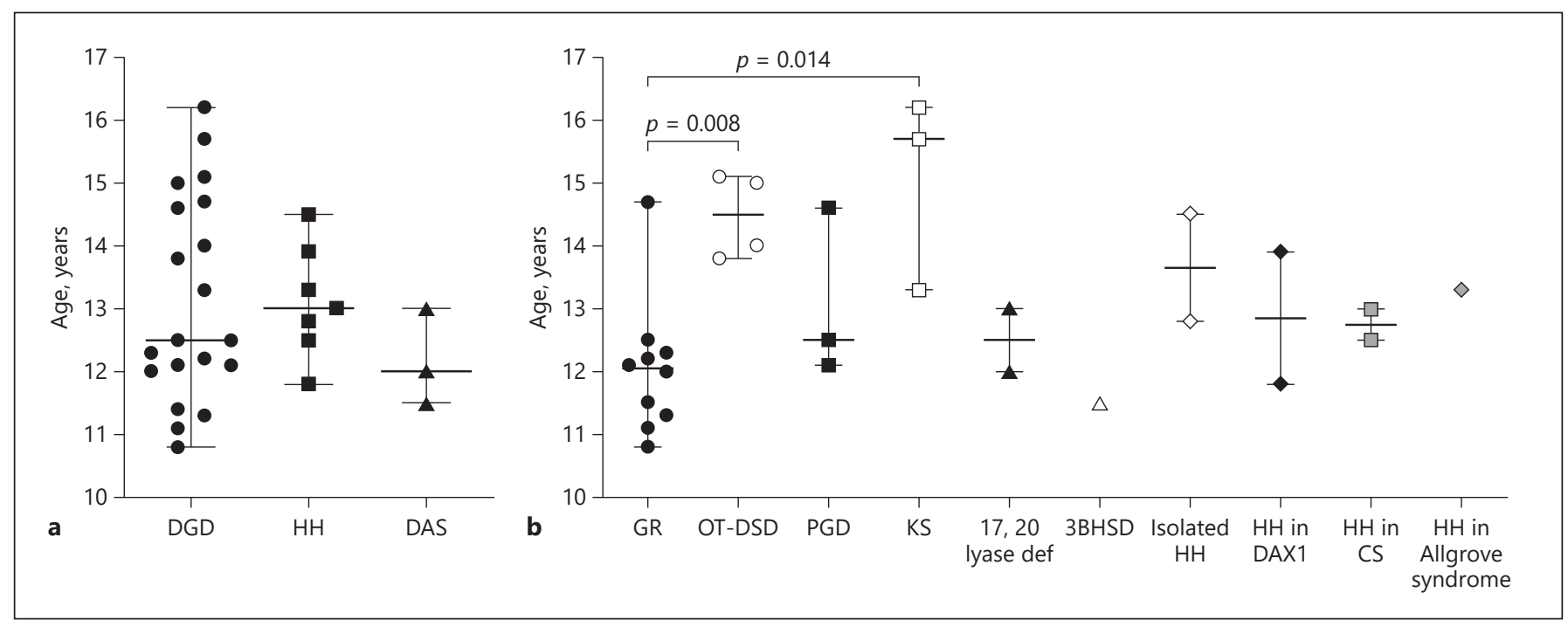

Fig. 1. a Median age (and range) at the start of testosterone ( $\mathrm{T}$ ) treatment according to disorder type. b Median age (and range) at the start of T treatment according to diagnosis. DGD, disorders of gonadal development; $\mathrm{HH}$, hypogonadotropic hypogonadism; DAS, disorders of androgen synthesis; GR, gonadal regression; OT-DSD, ovotesticular DSD; PGD, partial gonadal dysgenesis; KS, Klinefelter syndrome; 3BHSD, 3 $\beta$-hydroxysteroid dehydrogenase deficiency; CS, charge syndrom.

dian (range) age at the start of TRT was 12.6 years (10.816.2 ), and the median age at last assessment was 15.6 years (12-17.5). Median (range) age of boys not on TRT was 11.7 years (10.7-17.7), and 69 out of $132(52 \%)$ were $<12$ years. Of the 30 boys, 6 (20\%) started TRT before the age of 12 years: 4 with gonadal regression, 1 with $3 \beta$-hydroxysteroid dehydrogenase deficiency, and 1 with hypogonadotropic hypogonadism (Fig. 1). All those with hypogonadotropic hypogonadism were on TRT, and a substantial proportion of those with DGD ( $n$ $=20 ; 28 \%)$ and DAS $(n=3 ; 21 \%)$ were also on TRT $(\mathrm{Ta}-$ ble 1). However, none of the boys with PAIS, PMDS, or non-specific XY DSD were on TRT. Among the 15 boys diagnosed with PAIS, EMS at first presentation was available in 14 , and 12 of these $(86 \%)$ had an EMS $\geq 5$. The 3 boys with PGD who had started TRT included 2 who had undergone bilateral gonadectomy. There were another 2 boys with PGD with a median age of 11.7 years who had bilateral gonadectomy prepubertally and who had not started TRT at the time of study. The median age at starting therapy was broadly similar in the 3 subgroups of disorders (Fig. 1). However, the extent of variation in age at starting therapy was greater for those with DGD, and this was primarily because this group consisted of boys with gonadal regression who started at a younger age (Fig. 1).

Testosterone Therapy in Boys with Hypogonadism

\section{Testosterone Formulation}

The formulation of testosterone the 30 boys were started on included Sustanon ${ }^{\circledR}$, a blend of intramuscular testosterone esters ( $\mathrm{T}$ decanoate $40 \%$, T phenylproprionate $24 \%$, $\mathrm{T}$ isocaproate $24 \%$, T proprionate $12 \%$ ) in $14(47 \%)$ patients, intramuscular testosterone enanthate in 12 (40\%), oral testosterone undecanoate in $2(7 \%)$, and transdermal $2 \%$ testosterone gel in $2(7 \%)$. Of the 24 boys who had follow-up data, 10 (42\%) were on intramuscular Sustanon ${ }^{\circledR}, 8(33 \%)$ were on intramuscular testosterone enanthate, and $6(25 \%)$ were on transdermal $2 \%$ testosterone gel. One boy who was originally on oral testosterone undecanoate changed to intramuscular Sustanon ${ }^{\circledR}$, 1 changed from intramuscular Sustanon ${ }^{\circledR}$ to intramuscular testosterone enanthate, and 5 boys who were on intramuscular testosterone enanthate changed to transdermal $2 \%$ testosterone gel; these 5 boys were all at 1 centre.

\section{Monitoring of Therapy}

Before starting treatment, liver function and blood count were checked in 19 (68\%) and 18 boys (64\%), respectively. In addition, at start of therapy a radiological assessment of skeletal age was performed in 23 boys (82\%), and an assessment of bone mineral density (BMD) was performed by dual energy X-ray absorptiometry in 12 boys ( $43 \%)$. In the 24 boys with follow-up data, serum testosterone, liver function, and blood count had been 
monitored in 19 (79\%), 16 (67\%), and 15 boys (63\%), respectively, at either 12 or 18 monthly intervals. BMD had been performed in 8 boys (33\%) at an interval of 24 months. Adverse effects that were reported to be related to TRT included acne or oily skin in 3 boys, including 2 on intramuscular testosterone esters blend and 1 on oral testosterone undecanoate, aggressive behaviour in 1 boy on intramuscular testosterone esters blend, pain on injection in 1 boy on intramuscular testosterone esters blend, and a self-limiting episode of testicular pain in 1 boy on oral testosterone undecanoate.

\section{Discussion}

The current study represents the largest survey of TRT in boys with hypogonadism due to DSD or hypogonadotropic hypogonadism. It was designed to obtain a snapshot of contemporary practice, and boys within an age bracket where they would be currently receiving TRT were selected.

The occurrence of hypogonadism in boys and men with XY DSD has rarely been studied in detail. On systematic investigation of all boys presenting to an expert clinic with atypical genitalia, it is estimated that about a quarter may have an endocrine abnormality that may predispose them to long-term hypogonadism [Nixon et al., 2017]. However, it is possible that in some cases, hypogonadism may not be present in early childhood but develops over time with spontaneous testicular degeneration such as that observed in disorders of gonadal development associated with NR5A1-related partial gonadal dysgenesis [Tantawy et al., 2012] or Klinefelter syndrome. In some conditions such as undescended testes, hypogonadism may not be evident until adulthood [Rohayem et al., 2017] or may present after a procedure such as orchidopexy [Tseng et al., 2019]. Single-centre studies of adolescents suggest that in conditions such as partial gonadal dysgenesis, the occurrence of hypogonadism that presents overtly as pubertal delay may be as common as $40 \%$ [Gomes et al., 2018].

In the current study that included 15 centres, about a fifth of adolescent boys with a range of conditions were hypogonadal to such an extent that they required testosterone therapy for induction and maintenance of puberty. Within this large group of diverse conditions, about a quarter of those with a disorder of gonadal development or disorder of androgen synthesis were on testosterone. In addition, all boys who had hypogonadotropic hypogonadism were also on testosterone therapy. This latter finding is interesting to note given that opinion varies amongst specialists on whether to induce puberty with gonadotropins or testosterone [Han and Bouloux, 2010]. It is also possible that the availability of gonadotropins and the priority placed on fertility outcomes may have also influenced the therapeutic rationale. It was also important to note that none of the adolescents with PAIS were on testosterone therapy, and neither were those that had non-specific XY DSD who had normal gonadal function. Previous studies suggest that in adolescence, TRT may only be required by those who are severely undermasculinized as described by an EMS $<5$ [Lek et al., 2018]; most of the cohort in the current study had a greater EMS. Interestingly, in young adulthood, almost $50 \%$ of men with PAIS with a wide range of EMS receive testosterone supplementation [Lucas-Herald et al., 2016]. The findings of these studies in combination suggest that androgen supplementation in PAIS is more likely to be initiated for pubertal induction in boys who are particularly undermasculinised at first presentation, while a greater proportion of men with PAIS receive TRT in adulthood, perhaps for inadequate virilisation.

Whilst the age at starting TRT has been reported to be as low as 12 years in cases of permanent hypogonadism [Lucas-Herald et al., 2018], a fifth of the boys in the current cohort had initiation of therapy at an age $<12$ years and as early as 10 years. The practice of starting testosterone as early as 10 years was particularly evident in boys with gonadal regression. Given that there is unequivocal evidence of primary hypogonadism in these cases and the mean age for genital stage 2 has been reported in some population studies to be as young as 9.5 years [HermanGiddens et al., 2001], there is a possible rationale for starting testosterone early. However, most studies show that the age of attainment of genital stage 2 is between 11 and 12 years [Juul et al., 2006]. Some who are concerned about pubertal growth have suggested that TRT should be initiated after a bone age of 10.5 years [Mason et al., 2020]. In conditions other than bilateral anorchia or gonadal regression, it is possible that the adolescent may have a state of partial hypogonadism where onset and/or progression through puberty may be affected to a variable extent. In such cases, it would be appropriate to monitor growth and pubertal development as well as biochemical markers of puberty and wait until there are clear signs that indicate that normal pubertal progress is unlikely to occur. It is likely that the timing of starting TRT is linked to the diagnosis, but to analyse this relationship, there is a need to study a larger group of boys with specific and confirmed diagnoses. The largest homogenous group of boys in the 
current study who had TRT was the group of boys with gonadal regression, a condition which uniformly presents at a very early age. However, even in this group, the range of starting therapy was highly variable, ranging between 10.8 and 14.7 years. There is a need to gain further structured evidence of the rationale for the starting age of testosterone therapy as well as its relative benefits and harms.

It is clear that despite the availability of oral and topical forms of testosterone [Stancampiano et al., 2019], the intramuscular depot for testosterone remains the most popular form of therapy, confirming literature data [Drobac et al., 2006]. However, it was interesting to note that over time, the topical form of testosterone may be gaining popularity and there may be differences between centres. Comparison of different forms of testosterone therapy have rarely been performed [Ahmed et al., 2004; Chioma et al., 2018], and it is likely that the choice of preparation is based on local availability and preferences. However, in adult men with DSD, it seems that a greater proportion seem to be satisfied with non-parenteral forms of TRT [Nordenström et al., 2018]. Satisfaction with testosterone replacement has not been systematically assessed in adolescents and, in addition to markers of clinical efficacy, would benefit from being routinely assessed in the future. Reports of adverse effects were infrequent, but given that the study assessed these retrospectively, it is unclear whether these are sought routinely and whether they influence practice. Testosterone therapy in transgender adolescents has been associated with changes in metabolic parameters [Stoffers et al., 2019]. While it is possible that the likelihood of adverse effects of testosterone replacement may depend on the underlying condition, as suggested recently in a study of young men with thalassaemia [De Sanctis et al., 2019], there is a need to assess these effects systematically in all boys who embark on long-term testosterone replacement. Clinical trials of testosterone therapy that evaluate the efficacy and safety for pubertal induction are very rare [Stancampiano et al., 2019] and probably reflect the heterogeneity and the rarity of the conditions for which boys require TRT. Although it seems that liver function tests and haematology are assessed in the majority, this was not universal practice. Previously, guidance on the topic of monitoring TRT in adolescence has been published [Bertelloni et al., 2010; Soliman et al., 2014], and these have been revised recently [Stancampiano et al., 2019]. However, our experience from the current multicentre study, as well as previous studies [Nahata et al., 2015; Lucas-Herald et al., 2018], suggests that this guidance is not universally followed. Perhaps, this may also reflect the lack of evidence that

Testosterone Therapy in Boys with Hypogonadism supports the need for routine monitoring, as may be the case for regular assessment of BMD [Stancampiano et al., 2019]. In the absence of clinical trials and licensed forms of TRT, there is a need to standardize the monitoring of therapy of such infrequent practice and ensure systematic collection of real-world evidence.

For pragmatic reasons we chose to define hypogonadism as those boys on testosterone therapy. In those patients with conditions such as gonadal regression or congenital hypogonadotropic hypogonadism, it is likely that TRT was started before they developed any actual biochemical or physical signs of hypogonadism. However, in general, it is possible that the current study is an underestimate of the actual number of adolescents with hypogonadism given that this condition is a very wide spectrum and can include patients with biochemical hypogonadism [Grinspon et al., 2019]. The prevalence of overt or sub-clinical hypogonadism in boys has not been systematically studied to date. Rodie et al. [2011] reported that approximately 50 cases with suspected DSD may present per year for a population of approximately 3 million. Considering that in 2019 the estimated number of boys aged 10-19 years in the same area was 30,000 and that 24 boys included in the study were recruited from West of Scotland (https://www.understandingglasgow. com/indicators/population/trends/changing_age_structure, last accessed, May 2019), it could be considered that boys with DSD were well represented. However, this may not be valid for all centres, and there may have been some selection bias. It is also possible that clinicians may have chosen to report cases that were more severely affected or the centres that chose to participate or not to may have introduced a level of bias. However, the current study still represents the largest assessment of the contemporary practice of testosterone therapy in boys with a wide range of conditions that cause permanent hypogonadism. The results show that testosterone therapy in boys with DSD is not a common occurrence and that there is a wide extent of variation in practice. It is possible that this variation is due to multiple factors, such as the needs of the young person himself, the clinical outcomes that are considered important by the clinician, and the local availability of drugs. The results also stress the need for ongoing studies to monitor practice and highlight the need for guidelines and standardized protocols that can be used at the initiation and during maintenance of long-term testosterone therapy. Whilst the I-DSD Registry remains a valuable resource of cases of DSD, the study has also highlighted the need for developing a specific module within the Registry that focuses on capturing relevant informa- 
tion on TRT in a standardized manner. These protocols and resources will allow us to understand the rationale as well as the short- and long-term effects of TRT in boys with DSD.

\section{Acknowledgements}

This work would not have been possible without the children and the parents of the children with DSD whose data have been included in the I-DSD Registry. We would also like to express our thank for the support of the Office for Rare Conditions in Glasgow, the NIHR Cambridge Biomedical Research Centre, and the following reference centres that participate in the European Reference Network for Rare Endocrine Conditions (Endo-ERN): Ghent University Hospital; MHAT Sveta Marina, Varna; Azienda Ospedaliera Universitaria Sant'Orsola Malpighi, Bologna; Ospedale San Raffaele, Milan; Azienda Ospedaliera Universitaria Pisana, Pisa; Leiden University Medical Center; Erasmus Medical Center Rotterdam; Karolinska University Hospital, Stockholm; NHS Greater Glasgow and Clyde Board. Lastly, we are also grateful to Professor Rodolfo Rey for his assistance.

\section{Statement of Ethics}

The research was conducted ethically in accordance with the World Medical Association Declaration of Helsinki. The I-DSD Registry is an international database of pseudo-anonymized information deposited by clinicians following informed consent from the patient or their guardian. The Registry is approved by the National Research Ethics Service in the UK as a research database of information that is collected as part of routine clinical care.

\section{Conflict of Interest Statement}

S.F.A. has received consultant fees from Acerus Pharma. M.R.S. has received consultant fees from Neurocrine Pharma.

\section{Funding Sources}

The I-DSD Registry was developed using support from an unrestricted education grant from Diurnal Ltd and research grants from the Medical Research Council (G1100236), the Seventh European Union Framework Program (201444), and the European Society for Paediatric Endocrinology Research Unit.

\section{Author Contribution}

S.F.A., M.R.S., A.K.L.-H., and J.B, designed the study. M.R.S. analysed and interpreted the data. S.F.A. and M.R.S. wrote the manuscript. A.K.L.-H., J.B., G.R., G.B., A.B., F.B., S.B., M.V., M.C., L.J.W.T., F.D., S.P., E.G., R.G., S.E.H., I.A.H., R.T.-C., A.T., C.I., V.M., D.K., I.M., M.N., Z.K., A.N., and S.F.A. revised the manuscript critically and approved the final version.

\section{Data Availability}

The datasets generated or analysed during the current study are not available publicly but available to access through a data sharing agreement with the I-DSD Registry (www.i-dsd.org).

\section{References}

Ahmed SF, Khwaja O, Hughes IA. The role of a clinical score in the assessment of ambiguous genitalia. BJU Int. 2000;85:120-4.

Ahmed SF, Tucker P, Mayo A, Wallace AM, Hughes IA. Randomized, crossover comparison study of the short-term effect of oral testosterone undecanoate and intramuscular testosterone depot on linear growth and serum bone alkaline phosphatase. J Pediatr Endocrinol Metab. 2004;17: 941-50.

Ahmed SF, Rodie M, Jiang J, Sinnott RO. The European Disorder of Sex Development Registry: a virtual research environment. Sex Dev. 2010;4(4-5): 192-8.

Ali SR, Lucas-Herald A, Bryce J, Ahmed SF. The role of international databases in understanding the aetiology and consequences of differences/disorders of sex development. Int $\mathrm{J} \mathrm{Mol}$ Sci. 2019;20(18):4405.

Bertelloni S, Dati E, Baroncelli GI. Disorders of sex development: hormonal management in adolescence. Gynecol Endocrinol. 2008; 24(6):339-46
Bertelloni S, Baroncelli GI, Garofalo P, Cianfarani S. Androgen therapy in hypogonadal adolescent males. Horm Res Paediatr. 2010;74(4):292-6.

Chioma L, Papucci G, Fintini D, Cappa M. Use of testosterone gel compared to intramuscular formulation for puberty induction in males with constitutional delay of growth and puberty: a preliminary study. J Endocrinol Invest. 2018;41(2):259-63.

De Sanctis V, Soliman AT, Daar S, Di Maio S. Adverse events during testosterone replacement therapy in 95 young hypogonadal thalassemic men. Acta Biomed. 2019;90:228-32.

Drobac S, Rubin K, Rogol AD, Rosenfield RL. A workshop on pubertal hormone replacement options in the United States. J Pediatr Endocrinol Metab. 2006;19(1):55-64.

Dwyer AA, Phan-Hug F, Hauschild M, EloweGruau E, Pitteloud N. Transition in endocrinology: Hypogonadism in adolescence. Eur J Endocrinol. 2015;173(1):R15-24.

Gomes NL, Lerário AM, Machado AZ, Moraes DR, Silva TED, Arnhold IJP, et al. Long-term outcomes and molecular analysis of a large co- hort of patients with 46,XY disorder of sex development due to partial gonadal dysgenesis. Clin Endocrinol (Oxf). 2018;89(2):164-77.

Grinspon RP, Freire AV, Rey RA. Hypogonadism in pediatric health: adult medicine concepts fail. Trends Endocrinol Metab. 2019;30(12):879-90.

Han TS, Bouloux PM. What is the optimal therapy for young males with hypogonadotropic hypogonadism? Clin Endocrinol (Oxf). 2010; 72(6):731-7

Herman-Giddens ME, Wang L, Koch G. Secondary sexual characteristics in boys: estimates from the National Health and Nutrition Examination Survey III, 1988-1994. Arch Pediatr Adolesc Med. 2001;155(9):1022-8.

Juul A, Teilmann G, Scheike T, Hertel NT, Holm K, Laursen EM, et al. Pubertal development in Danish children: comparison of recent European and US data. Int J Androl. 2006;29(1):247-90.

Kolesinska Z, Ahmed SF, Niedziela M, Bryce J, Molinska-Glura M, Rodie M, et al. Changes over time in sex assignment for Disorders of Sex Development. Pediatrics. 2014;134(3): e710-5. 
Kyriakou A, Dessens A, Bryce J, Iotova V, Juul A, Krawczynski M, et al. Current models of care for disorders of sex development - results from an International survey of specialist centres. Orphanet J Rare Dis. 2016;11(1):155.

Lek N, Tadokoro-Cuccaro R, Whitchurch JB, Mazumder B, Miles H, Prentice P, et al. Predicting puberty in partial androgen insensitivity syndrome: use of clinical and functional androgen receptor indices. EBioMedicine. 2018;36:401-9.

Lucas-Herald A, Bertelloni S, Juul A, Bryce J, Jiang J, Rodie $\mathrm{M}$, et al. The long-term outcome of boys with partial androgen insensitivity syndrome and a mutation in the androgen receptor gene. J Clin Endocrinol Metab. 2016 Nov;101(11):3959-67.

Lucas-Herald AK, Mason E, Beaumont P, Mason A, Shaikh MG, Wong SC, et al. Single-centre experience of testosterone therapy for boys with hypogonadism. Horm Res Paediatr. 2018;90(2):123-7.

Mason KA, Schoelwer MJ, Rogol AD. Androgens during infancy, childhood, and adolescence: physiology and use in clinical practice. Endocr Rev. 2020;41(3):41.
Nahata L, Yu RN, Bhasin S, Cohen LE. Management of testosterone therapy in adolescents and young men with hypogonadism: are we following adult clinical practice guidelines? J Pediatr Endocrinol Metab. 2015;28(5-6): 635-40.

Nixon R, Cerqueira V, Kyriakou A, Lucas-Herald A, McNeilly J, McMillan M, et al. Prevalence of endocrine and genetic abnormalities in boys evaluated systematically for a disorder of sex development. Hum Reprod. 2017;32(10): $2130-7$.

Nordenström A, Röhle R, Thyen U, Bouvattier C, Slowikowska-Hilczer J, Reisch N, et al. Hormone therapy and patient satisfaction with treatment, in a large cohort of diverse disorders of sex development. Clin Endocrinol (Oxf). 2018;88(3):397-408.

Rodie M, McGowan R, Mayo A, Midgley P, Driver CP, Kinney M, et al. Factors that influence the decision to perform a karyotype in suspected Disorders of Sex Development: lessons from the Scottish Genital Anomaly Network Register. Sex Dev. 2011;5(3):103-8.
Rohayem J, Luberto A, Nieschlag E, Zitzmann M, Kliesch S. Delayed treatment of undescended testes may promote hypogonadism and infertility. Endocrine. 2017;55(3):914-24.

Soliman A, Sanctis V, Yassin M. Androgen therapy in adolescents: a review. Andrology. 2014; 3:124

Stancampiano MR, Lucas-Herald AK, Russo G, Rogol AD, Ahmed SF. Testosterone therapy in adolescent boys: The need for a structured approach. Horm Res Paediatr. 2019;92:21528.

Stoffers IE, de Vries MC, Hannema SE. Physical changes, laboratory parameters, and bone mineral density during testosterone treatment in adolescents with gender dysphoria. J Sex Med. 2019;16(9):1459-68.

Tantawy S, Lin L, Akkurt I, Borck G, Klingmüller D, Hauffa BP, et al. Testosterone production during puberty in two 46,XY patients with disorders of sex development and novel NR5A1 (SF-1) mutations. Eur J Endocrinol. 2012;167(1):125-30.

Tseng CS, Huang KH, Kuo MC, Hong CH, Chen $\mathrm{CH}, \mathrm{Lu} \mathrm{YC}$, et al. The impact of primary location and age at orchiopexy on testicular atrophy for congenital undescended testis. Sci Rep. 2019;9(1):9489. 